\title{
Postcardiotomy Extracorporeal Membrane Oxygenation in Neonates
}

\author{
Xindi Yu ${ }^{1}$ Yinyu Yang ${ }^{1}$ Wei Zhang ${ }^{1}$ Zheng Guo ${ }^{1}$ jia Shen ${ }^{1}$ Zhuoming $\mathrm{Xu}^{1}$ Haibo Zhang ${ }^{1}$ \\ Wei Wang ${ }^{1}$ \\ ${ }^{1}$ Department of Pediatric Thoracic and Cardiovascular Surgery, \\ Shanghai Children's Medical Center, Shanghai Jiaotong University \\ School of Medicine, Shanghai, China \\ Address for correspondence Wei Wang, MD, PhD, No. 1678 Dong \\ Fang Road, Shanghai 200127, China \\ (e-mail: wangwei@scmc.com.cn).
}

Thorac Cardiovasc Surg 2021;69:e41-e47.

\begin{abstract}
Keywords

- neonate

- extracorporeal membrane oxygenation

- congenital heart disease

- open heart surgery

Background Extracorporeal membrane oxygenation (ECMO) provides circulatory support in children with congenital heart disease, particularly in the setting of cardiopulmonary failure and inability to wean from cardiopulmonary bypass. This study summarized the clinical application of ECMO in the treatment of heart failure after cardiac surgery in neonates.

Materials and Methods Clinical data of 23 neonates who received ECMO support in our center from January 2017 to June 2019 were retrospectively analyzed.

Results Twenty-three neonates, aged from 0 to 25 days and weight between 2,300 and $4,500 \mathrm{~g}$, with heart failure postcardiotomy were supported with ECMO. The successful weaning rate was $78.26 \%$ and discharge rate was $52.17 \%$. Bleeding and residual malformation were the most common complications. The univariate analysis showed that nonsurvivors were related to the factors such as higher lactate value of ECMO 12 and 24 hours $(p=0.008$ and 0.001 , respectively), longer time to lactate normalization $(p=0.001)$, lactate $>10 \mathrm{mmol} / \mathrm{L}$ before ECMO $(p=0.01)$, lower weight $(p=0.01)$, longer ECMO duration $(p=0.005)$, lower platelet count $(p=0.001)$, more surgical site bleeding $(p=0.001)$, and surgical residual malformation $(p=0.04)$. Further logistic regression analysis revealed that higher lactate value of ECMO 24 hours $(p=0.003)$, longer ECMO duration ( $p=0.015)$, and surgical site bleeding $(p=0.025)$ were independent risk factors. Conclusion ECMO was an effective technology to support the neonates with cardiopulmonary failure after open heart surgery. Control the lactate acidosis and surgical site bleeding event may be helpful for patients' recovery.
\end{abstract}

\section{Introduction}

Extracorporeal membrane oxygenation (ECMO) is an important technology, which can be used for severe heart failure. ${ }^{1,2}$ Since the first successful ECMO application in a newborn in $1975,{ }^{3}$ more than 85,000 neonates treated with ECMO have been reported to Extracorporeal Life Support Organization

received

December 28, 2020 accepted after revision April 7, 2021
DOI https://doi.org/ 10.1055/s-0041-1730034. ISSN 0171-6425.
(ELSO) nowadays. In China, ECMO has been practiced for two decades, but most patients are adults. As more children undergoing cardiac surgery may require ECMO support for cardiorespiratory failure, ${ }^{4}$ pediatric ECMO applications have increased and reported in recent years. However, among the numerous studies investigating the utility and risk factors associated with ECMO in pediatric cardiac patients, few

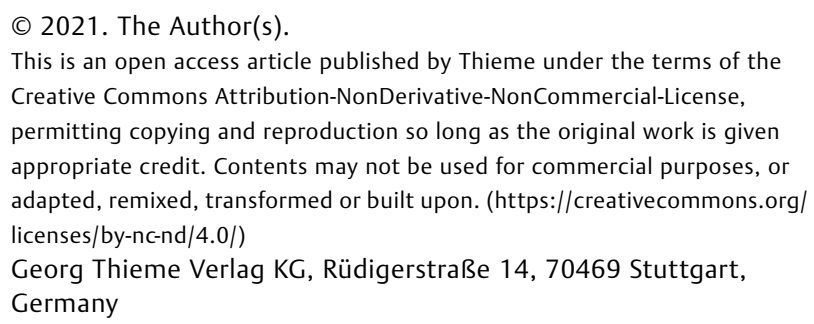


specifically address patients with neonatal heart disease. In this study, we conducted a retrospective review of neonates who undergone ECMO at Shanghai Children's Medical Center (SCMC) and summarized the clinical application of ECMO in the treatment of heart failure after neonatal cardiac surgery.

\section{Materials and Methods}

\section{Patient Characteristics}

The current study was approved by the Institutional Review Board of the Shanghai SCMC affiliated to Shanghai Jiaotong University School of Medicine. As the study design was a retrospective review of collected data, the need for informed consent was waived. From January 2017 to June 2019, 9,354 cases with congenital heart disease (CHD) were undergone open heart surgery in SCMC and 441 were neonates, 27 cases required support postoperatively (26 venoarterial [VA]-ECMO cases and 1 ventricular-assist device case). The ventricular assist device infant and three children supported with ECMO less than 24 hours were excluded, and 23 patients (15 males and 8 females) were analyzed. Mean age was $9.08 \pm 8.02$ days (range: $0-25$ days) and mean birth weight was 3,170 $\pm 535 \mathrm{~g}$ (range: 2,300-4,500 g). The diseases were interrupted aortic arch/coarctation of the aorta $(n=10)$, D-transposition of the great artery $(n=8)$, pulmonary atresia $(n=2)$, total anomalous pulmonary venous connection $(n=1)$, double outlet right ventricle $(n=1)$, and coronary artery-right ventricular fistula $(n=1)$.

\section{Clinical Data}

Successful weaning was defined as weaning without reinsertion of ECMO or death within 24 hours. Clinical variables were collected: indication of ECMO, intensive care unit details, and complications. The lactate clearance time means that the time required for the body's lactate value to fall from the maximum to $<2 \mathrm{mmol} / \mathrm{L}$.

\section{Complications}

Complications were categorized: (1) surgical site bleeding (cannulation or surgical site bleeding requiring an intervention); (2) brain injury (central nervous system hemorrhage, infarction causing ischemic injury); (3) gastrointestinal (GI) bleeding (fecal occult blood test is positive, hematemesis, melena, or bloody stool); (4) mechanical complication (oxygenator or pump failure, air in circuits); (5) infection (culture positive infection); (6) residual malformation (residual shunt or obstruction, moderate or severe reflux).

\section{ECMO Details and Management}

In our institution, for all subjects, we recorded indication for therapy (defined as postcardiotomy shock, fail to transition from cardiopulmonary bypass [CPB], low cardiac output syndrome [LCOS], extracorporeal cardiopulmonary resuscitation [ECPR], or other). Neonates were cannulated for ECMO by pediatric cardiovascular surgeons and underwent cannulation through the right atrium and common ascending aorta. Typically, 8 to $10 \mathrm{Fr}$ cannulas were used for arterial cannulation and 14 to $16 \mathrm{Fr}$ for venous access.
The standard circuit includes a centrifugal pump and HI-LITE 800LT hollow-fiber membrane oxygenator. The goal of ECMO treatment is to use sufficient flow to maintain the children's systemic circulation. Therefore, it is necessary to gradually reduce the dose of positive inotropic drugs in the initial phase, and maintain a high flow of 130 to $180 \mathrm{~mL} / \mathrm{kg} / \mathrm{min}$ with the average arterial blood pressure at 40 to $60 \mathrm{~mm} \mathrm{Hg}$ and the ventilator was adjusted to rest settings. The doctors adjust the flow according to changes in the heart function, hemodynamics, lactic acid level, blood gas results, and so on. When urine output fell to $<1$ to $2 \mathrm{~mL} / \mathrm{kg} / \mathrm{h}$, diuretics were given to promote diuresis. If neonates experienced severe renal impairment and low urine volume, continuous renal replacement therapy (CRRT) which was connected to the ECMO circuit was started immediately, and continuous venovenous hemodiafiltration treatment was used often.

The standard anticoagulation is unfractionated heparin, ranging 5 to 40 units $/ \mathrm{kg} / \mathrm{h}$ which was administered to keep activated clotting time (ACT) level at 160 to 200 seconds and activated partial thromboplastin time (APTT) between 50 and 70 seconds. ACT and APTT levels were monitored every 4 hours, and antithrombin (AT)III, platelet (PLT) count, hematocrit (HCT) and fibrinogen levels were monitored every 24 hours, unless otherwise indicated. The blood components were transfused if $\mathrm{HCT}<35 \%$, PLT count $<50 \times 10^{9} / \mathrm{L}$, AT $<83 \%$, and fibrinogen $<1.5 \mathrm{~g} / \mathrm{L}$.

Cardiac filling degree, ventricular systolic/diastolic status, ejection fraction, and residual lesions were evaluated daily by transthoracic echocardiography. With the improvement of the clinical condition, if the neonate's hemodynamic status was stable at $50 \mathrm{~mL} / \mathrm{kg} / \mathrm{min}$ pump flow, decannulation was anticipated.

\section{Statistical Analysis}

Statistical analysis was performed using SPSS22 for windows. Quantitative variables are presented as mean \pm standard deviation when normally distributed, or as median (interquartile range) if nonnormally distributed. Independent $t$-test and chi-square test were used to compare baseline characteristics between groups. We used univariate analysis and multivariable logistic regression to evaluate the risk factors with nonsurvivors. The $p<0.05$ were considered statistically significant.

\section{Results}

\section{Characteristics}

Twenty-three neonates with heart failure after open heart surgery were undergone ECMO, and two were premature infants and three were less than $2,500 \mathrm{~g}$. Eighteen cases (78.26\%) were weaned off ECMO and 12 (52.17\%) discharged successfully (-Table $\mathbf{1}$ ).

The indications were categorized into ECPR, inability to wean from CPB, and LCOS in 8, 5, and 10 cases. Of the ECPR neonates, four patients discharged (hypoperfusion time $\leq 30$ minutes), and four patients died finally (hypoperfusion time $>30$ minutes $)(p=0.005)$. Five neonates, inability to wean from $\mathrm{CPB}$, were weaned successfully, and just one survived. Ten cases 
Table 1 Clinical characteristics

\begin{tabular}{|c|c|c|c|c|}
\hline Classification & Overall $(N=23), \%$ & Survivors $(N=12), \%$ & Nonsurvivors $(N=11), \%$ & $p$-Value \\
\hline \multicolumn{5}{|l|}{ Gender } \\
\hline Male & 15 & $7(58.33)$ & $8(72.73)$ & \multirow[t]{2}{*}{0.46} \\
\hline Female & 8 & $5(41.67)$ & $3(27.27)$ & \\
\hline \multicolumn{5}{|l|}{ Body weight (kg) } \\
\hline$\leq 2.49$ & $3(13.04)$ & $1(8.33)$ & $2(18.18)$ & \multirow[t]{4}{*}{0.098} \\
\hline $2.50-2.99$ & $6(26.09)$ & $1(8.33)$ & $5(45.45)$ & \\
\hline $3-3.99$ & $12(52.17)$ & $8(66.66)$ & $4(36.36)$ & \\
\hline$\geq 4$ & $2(8.70)$ & $2(16.67)$ & 0 & \\
\hline \multicolumn{5}{|l|}{ Age $(d)$} \\
\hline Premature neonate & $2(8.70)$ & $1(8.33)$ & $1(9.09)$ & \multirow[t]{4}{*}{0.14} \\
\hline$<7$ & $9(39.13)$ & $7(58.33)$ & $2(18.18)$ & \\
\hline $7-14$ & $6(26.09)$ & $1(8.33)$ & $5(45.45)$ & \\
\hline $14-30$ & $6(26.09)$ & $3(25)$ & $3(27.27)$ & \\
\hline \multicolumn{5}{|l|}{ Cardiac defect } \\
\hline CoA/IAA/VSD & $10(43.48)$ & $6(50)$ & $4(36.36)$ & \multirow[t]{6}{*}{0.56} \\
\hline TGA & $8(34.78)$ & $5(41.67)$ & $3(27.27)$ & \\
\hline TAPVC & $1(4.35)$ & 0 & $1(9.09)$ & \\
\hline $\mathrm{PA} / \mathrm{IVS}$ & $2(8.70)$ & $1(8.33)$ & $1(9.09)$ & \\
\hline DORV & $1(4.35)$ & 0 & $1(9.09)$ & \\
\hline $\begin{array}{l}\text { Coronary artery-right } \\
\text { ventricular fistula }\end{array}$ & $1(4.35)$ & 0 & $1(9.09)$ & \\
\hline \multicolumn{5}{|l|}{ Indication } \\
\hline LCOS & $10(43.48)$ & $7(58.33)$ & $3(27.27)$ & \multirow[t]{3}{*}{0.18} \\
\hline Unable to wean off CPB & $5(21.74)$ & $1(8.33)$ & $4(36.36)$ & \\
\hline ECPR & $8(34.78)$ & $4(33.33)$ & $4(36.36)$ & \\
\hline \multicolumn{5}{|l|}{ Hypoperfusion time (min) } \\
\hline$\leq 30$ & $4(16.67)$ & $4(30.77)$ & 0 & \multirow[t]{2}{*}{0.005} \\
\hline$>30$ & $4(16.67)$ & 0 & $4(36.36)$ & \\
\hline \multicolumn{5}{|l|}{ ECMO duration $(\mathrm{d})$} \\
\hline $1-3$ & $8(34.78)$ & $5(41.67)$ & $3(27.27)$ & \multirow[t]{3}{*}{0.01} \\
\hline $3-5$ & $9(39.13)$ & $7(58.33)$ & $2(18.18)$ & \\
\hline$>5$ & $6(26.09)$ & 0 & $6(54.55)$ & \\
\hline Successful weaning & $18(78.26)$ & $12(100)$ & $6(54.55)$ & \\
\hline
\end{tabular}

Abbreviations: COA, coarctation of the aorta; CPB, cardiopulmonary bypass; DORV, double outlet right ventricle; ECMO, extracorporeal membrane oxygenation; ECPR, extracorporeal cardiopulmonary resuscitation; IAA, interrupted aortic arch; LCOS, low cardiac output syndrome; PA/IVS, pulmonary atresia with intact ventricular septum; TAPVC, total anomalous pulmonary venous connection; TGA, transposition of the great arteries; VSD, ventricular septal defect.

had LCOS, nine (90\%) were weaned successfully, and seven (70\%) discharged.

The duration of ECMO support was between 38 and 456 hours. There were eight neonates weaned off ECMO in 3 days and five survived; nine patients between 3 and 5 days and seven survived; and six neonates above 5 days and all $\operatorname{died}(p=0.01)$.

\section{Outcomes}

Compared with the survivors, the weights of the nonsurvivors were lighter ( $3.11 \pm 0.67$ vs. $3.43 \pm 0.49 \mathrm{~kg}, p=0.01$ ), and ECMO duration ( $145.09 \pm 90.38$ vs. $78.92 \pm 17.36$ hours, $p=0.046$ ) was significantly longer. The nonsurvivors had less time after surgery to ECMO $(7.01 \pm 3.15$ vs. $9.25 \pm 4.28$ hours, $p=0.03)$, higher the highest lactate levels $(18.34 \pm 5.13$ vs. $13.87 \pm 4.19$ $\mathrm{mmol} / \mathrm{L}, p=0.03$ ), higher lactate value of ECMO 12 hours $(9.24 \pm 3.70$ vs. $\quad 4.76 \pm 2.49 \mathrm{mmol} / \mathrm{L}, \quad p=0.005), \quad 24$ hours $(5.36 \pm 2.13$ vs. $2.27 \pm 1.05 \mathrm{mmol} / \mathrm{L}, p=0.001)$, more time to lactate normalization $(59.34 \pm 21.15$ vs. $25.01 \pm 13.50$ hours, $p=0.036)$, higher peak creatinine values $(151.29 \pm 68.28$ vs. $70.54 \pm 30.66 \mathrm{mg} / \mathrm{dL}, p=0.03$ ), and blood transfusion volume $(275.86 \pm 100.90$ vs. $88.51 \pm 30.24 \mathrm{~mL} / \mathrm{d}, p=0.04)$. The lowest 
Table 2 Comparison of clinical information between two groups

\begin{tabular}{|c|c|c|c|c|}
\hline Classification & Overall $(N=23)$ & Survivors $(N=12)$ & Nonsurvivors $(N=11)$ & $p$-Value \\
\hline Weight (kg) & $3.17 \pm 0.53$ & $3.43 \pm 0.49$ & $3.11 \pm 0.67$ & 0.01 \\
\hline CPB time (min) & $168.48 \pm 93.70$ & $155.45 \pm 54.14$ & $185.93 \pm 134.37$ & 0.23 \\
\hline Clamp time (min) & $90.22 \pm 53.92$ & $88.91 \pm 15.52$ & $97.23 \pm 74.28$ & 0.55 \\
\hline ECMO duration (h) & $109.48 \pm 63.03$ & $78.92 \pm 17.36$ & $145.09 \pm 90.38$ & 0.046 \\
\hline Ventilator duration (d) & $12.92 \pm 4.45$ & $16.42 \pm 4.74$ & $10.82 \pm 3.91$ & 0.035 \\
\hline ICU duration (d) & $18.04 \pm 7.58$ & $23.83 \pm 8.72$ & $10.39 \pm 5.76$ & 0.007 \\
\hline Length of hospitalization (d) & $24.25 \pm 9.79$ & $34.83 \pm 11.73$ & $11.64 \pm 7.63$ & 0.01 \\
\hline Time after surgery to ECMO (h) & $9.01 \pm 3.80$ & $9.25 \pm 4.28$ & $7.01 \pm 3.15$ & 0.03 \\
\hline The highest lactate $(\mathrm{mmol} / \mathrm{L})$ & $15.03 \pm 4.97$ & $13.87 \pm 4.19$ & $18.34 \pm 5.13$ & 0.03 \\
\hline Lactate of ECMO $12 \mathrm{~h}(\mathrm{mmol} / \mathrm{L})$ & $6.34 \pm 3.41$ & $4.76 \pm 2.49$ & $9.24 \pm 3.70$ & 0.005 \\
\hline Lactate of ECMO $24 \mathrm{~h}(\mathrm{mmol} / \mathrm{L})$ & $3.33 \pm 1.78$ & $2.27 \pm 1.05$ & $5.36 \pm 2.13$ & 0.001 \\
\hline Time to lactate normalization ( $<2 \mathrm{mmol} / \mathrm{L}, \mathrm{h})$ & $40.29 \pm 18.46$ & $25.01 \pm 13.50$ & $59.34 \pm 21.15$ & 0.036 \\
\hline Pump flow of ECMO $12-72 \mathrm{~h}(\mathrm{~mL} / \mathrm{kg} / \mathrm{min})$ & $157.29 \pm 21.32$ & $160.30 \pm 19.00$ & $155.77 \pm 22.54$ & 0.49 \\
\hline Ejection fraction of weaning from ECMO (\%) & $53.41 \pm 13.47$ & $57.36 \pm 13.12$ & $46.64 \pm 14.82$ & 0.06 \\
\hline Peak creatinine(mg/dL) & $119.22 \pm 50.49$ & $70.54 \pm 30.66$ & $151.29 \pm 68.28$ & 0.03 \\
\hline Peak ALT (IU/L) & $44.06 \pm 30.15$ & $36.20 \pm 26.02$ & $51.32 \pm 38.52$ & 0.12 \\
\hline Peak AST (IU/L) & $201.83 \pm 133.56$ & $156.88 \pm 121.71$ & $238.27 \pm 169.50$ & 0.26 \\
\hline Lowest PLT count $\left(\times 10^{9} / \mathrm{L}\right)$ & $38.05 \pm 18.77$ & $48.10 \pm 20.03$ & $30.90 \pm 18.14$ & 0.03 \\
\hline Blood transfusion $(\mathrm{mL} / \mathrm{d})$ & $193.77 \pm 97.18$ & $88.51 \pm 30.24$ & $275.86 \pm 100.90$ & 0.04 \\
\hline PLT transfusion $(\mathrm{mL} / \mathrm{d})$ & $70.87 \pm 36.28$ & $55.01 \pm 22.82$ & $86.43 \pm 42.2$ & 0.31 \\
\hline FFP and plasma transfusion (mL/d) & $168.56 \pm 67.64$ & $98.00 \pm 55.76$ & $247.14 \pm 86.35$ & 0.18 \\
\hline Surgical site bleeding, $n(\%)$ & $16(69.57)$ & $5(41.66)$ & $11(100)$ & 0.002 \\
\hline Intracranial hemorrhage, $n$ (\%) & $10(43.48)$ & $6(50)$ & $4(36.36)$ & 0.50 \\
\hline ECPR, $n(\%)$ & $8(34.78)$ & $4(33.33)$ & $4(36.36)$ & 0.87 \\
\hline Pre-ECMO lactate $<10 \mathrm{mmol} / \mathrm{L}, n(\%)$ & $5(21.74)$ & $4(33.33)$ & $1(9.09)$ & 0.10 \\
\hline Pre-ECMO lactate $>10 \mathrm{mmol} / \mathrm{L}, n(\%)$ & $18(78.26)$ & $7(58.33)$ & $11(100)$ & 0.01 \\
\hline Surgical residual malformation, $n(\%)$ & $6(26.09)$ & $1(8.33)$ & $5(45.45)$ & 0.04 \\
\hline Renal failure, $n(\%)$ & $5(21.74)$ & $2(16.67)$ & $3(27.27)$ & 0.53 \\
\hline GI bleeding, $n(\%)$ & $4(17.39)$ & $1(8.33)$ & $3(27.27)$ & 0.23 \\
\hline
\end{tabular}

Abbreviations: ALT, alanine aminotransferase; AST, aspartate aminotransferase; CPB, cardiopulmonary bypass; ECMO, extracorporeal membrane oxygenation; ECPR, extracorporeal cardiopulmonary resuscitation; FFP, fresh frozen plasma; GI, gastrointestinal; PLT, platelet.

PLT count was significantly lower in nonsurvivors than survivors $(p=0.03)$. The relationship between surgical site bleeding, lactic acid $>10 \mathrm{mmol} / \mathrm{L}$ before ECMO, and residual malformation on nonsurvivors was statistically significant $(p=0.002,0.01$, and 0.04 , respectively). There was no statistical difference between CPB time, clamp time, pump flow of ECMO 12 to 72 hours, ejection fraction of weaning from ECMO, the peak alanine aminotransferase and aspartate aminotransferase values, intracranial hemorrhage, GI bleeding, renal failure, and ECPR $(p>0.05)(-$ Table 2).

\section{Univariate and Logistic Regression Analysis Results}

The univariate analysis showed that nonsurvivors were related to the factors: higher lactate value of ECMO 12 and 24 hours $(9.24 \pm 3.70$ vs. $4.76 \pm 2.49 \mathrm{mmol} / \mathrm{L}, p=0.008$ and $5.36 \pm 2.10$ vs. $2.27 \pm 1.05 \mathrm{mmol} / \mathrm{L}, p=0.001$, respectively), longer time to lactate normalization $(59.34 \pm 21.13$ vs. $25.01 \pm 13.50$ hours, $p=0.001)$, lower weight $(3.11 \pm 0.67$ vs. $3.43 \pm 0.49 \mathrm{~kg}$, $p=0.001)$, longer ECMO time (145.02 \pm 90.25 vs. $78.92 \pm 17.31$ hours, $p=0.005$ ), lower the lowest PLT count ( $30.90 \pm 18.14$ vs. $\left.48.10 \pm 20.03 \times 10^{9} / \mathrm{L}, p=0.001\right)$, more surgical site bleeding (11 vs. $5, p=0.001$ ) and surgical residual malformation ( 5 vs. 1 , $p=0.04)$. Further logistic regression analysis revealed that higher lactate value of ECMO 24 hours $(p=0.003)$, longer ECMO duration $(p=0.015)$, and more surgical site bleeding event $(p=0.025)$ were independent risk factors for nonsurvivors ( - Table 3$)$.

\section{Causes of Death}

The mortality rate was $47.83 \%$ (11/23), six neonates were weaned successfully but died finally. Among the six patients, five had residual anatomical problems, even the heart function 
Table 3 Univariate analysis and multivariate logistic regression results

\begin{tabular}{|c|c|c|c|c|c|c|c|}
\hline \multirow[t]{2}{*}{ Classification } & \multirow[t]{2}{*}{ Survivors } & \multirow[t]{2}{*}{ Nonsurvivors } & \multicolumn{2}{|c|}{$\begin{array}{l}\text { Univariate } \\
\text { analysis }\end{array}$} & \multicolumn{3}{|c|}{$\begin{array}{l}\text { Multivariate logistic } \\
\text { regression }\end{array}$} \\
\hline & & & $F$ & $p$-Value & OR & $95 \% \mathrm{Cl}$ & $p$-Value \\
\hline Weight (kg) & $3.43 \pm 0.49$ & $3.11 \pm 0.67$ & 7.90 & 0.01 & & & \\
\hline ECMO duration (h) & $78.92 \pm 17.31$ & $145.02 \pm 90.25$ & 9.62 & 0.005 & 0.75 & $0.29-0.94$ & 0.015 \\
\hline Time after surgery to ECMO (h) & $9.25 \pm 4.28$ & $7.01 \pm 3.15$ & 1.46 & 0.24 & & & \\
\hline The highest lactate $(\mathrm{mmol} / \mathrm{L})$ & $13.87 \pm 4.19$ & $18.34 \pm 5.13$ & 1.83 & 0.19 & & & \\
\hline Lactate of ECMO $12 \mathrm{~h}(\mathrm{mmol} / \mathrm{L})$ & $4.76 \pm 2.49$ & $9.24 \pm 3.70$ & 8.55 & 0.008 & 2.55 & $0.42-10.33$ & 0.38 \\
\hline Lactate of ECMO $24 \mathrm{~h}(\mathrm{mmol} / \mathrm{L})$ & $2.27 \pm 1.05$ & $5.36 \pm 2.10$ & 101.41 & 0.001 & 13.87 & $2.33-18.84$ & 0.003 \\
\hline $\begin{array}{l}\text { Time to lactate normalization } \\
(<2 \mathrm{mmol} / \mathrm{L}, \mathrm{h})\end{array}$ & $25.01 \pm 13.50$ & $59.34 \pm 21.13$ & 22.75 & 0.001 & 3.88 & $0.96-4.06$ & 0.07 \\
\hline Peak creatinine $(\mathrm{mg} / \mathrm{dL})$ & $70.54 \pm 30.66$ & $151.29 \pm 65.28$ & 2.98 & 0.10 & & & \\
\hline Lowest PLT count $(\times 109 / L)$ & $48.10 \pm 20.03$ & $30.90 \pm 18.14$ & 42.51 & 0.001 & 3.62 & $0.92-1.90$ & 0.06 \\
\hline Blood transfusion $(\mathrm{mL} / \mathrm{d})$ & $88.51 \pm 30.24$ & $275.86 \pm 100.90$ & 5.11 & 0.05 & & & \\
\hline Surgical site bleeding, $n(\%)$ & $5(41.66)$ & $11(100)$ & 16.13 & 0.001 & 7.41 & $1.28-43.41$ & 0.03 \\
\hline Pre-ECMO lactate $>10 \mathrm{mmol} / \mathrm{L}, n(\%)$ & $7(58.33)$ & $11(100)$ & 3.35 & 0.08 & & & \\
\hline Surgical residual malformation, $n$ (\%) & $1(8.33)$ & $5(45.45)$ & 5.12 & 0.04 & & & \\
\hline
\end{tabular}

Abbreviations: $\mathrm{Cl}$, confidence interval; ECMO, extracorporeal membrane oxygenation; OR, odds ratio; PLT, platelet.

recovered during ECMO, but follow-up was not sustainable. Three cases involved GI bleeding with unstable circulatory function. Two cases failed to undergo further correction for renal failure, medical cost, and heart failure reasons, no further interventions were provided, and eventually both of them failed to wean.

\section{Complications}

\section{Surgical Site Bleeding}

Major bleeding requiring re-exploration occurred in 16 (69.57\%) patients. Eleven (68.75\%) patients were explored in the first 24 hours. Five had no initial major bleeding but required exploration later in the ECMO run for "late bleeding." Survival rate in the explored group was five (31.25\%). Survival rates for early bleeding versus late bleeding were 25 and $6.25 \%(p=0.51)$ (-Table 2 ).

\section{Nervous System Injury}

Ten (43.48\%) infants had central nervous system injury, but only six survived. Overall neurological injury included intracranial bleeding $(n=8,34.78 \%)$ and ischemic brain injury $(n=2,8.70 \%$ ). Five cases had neurological bleeding and surgical site bleeding simultaneously.

\section{Renal Failure}

The incidence of renal failure requiring CRRT was five (21.74\%), only two patients survived. None of the survivors required long-term dialysis after hospital discharge $(p=0.53)$.

\section{GI Bleeding}

GI bleeding was a serious complication. Among four neonates, only one survived. Two (50\%) neonates needed laparotomies, but failed to undergo further correction.

\section{Other Complications}

Other complications included cardiac tamponade $(n=5$, $21.74 \%)$, arrhythmia ( $n=4,17.39 \%)$, liver function damage ( $n=4,17.39 \%)$, infection $(n=3,13.04 \%)$, and clots in the ECMO circuit ( $n=2,8.70 \%)$.

\section{Residual Anatomical Malformation}

Another serious issue was residual anatomical problems $(26.09 \%, n=6)$. Only one patient who undergone reoperation survived. Three patients involved residual ventricular septal shunt and residual aortic arch obstruction, and two patients had postoperative aortic valve insufficiency. Although several patients weaned successfully, they died finally due to recurrent heart failure.

\section{Discussion}

ECMO is commonly used in pediatric patients with CHD, particularly in the setting of low-output failure, arrhythmia, cardiopulmonary arrest, or inability to wean from CPB. ${ }^{5}$ However, despite significant advances in ECMO techniques and management over the past several years, prognosis remains poor. ${ }^{6}$ The underlying causes of death vary from cardiovascular events to organ failure, including GI, renal, neurologic, coagulation, and it carries a significant cost burden. ${ }^{7}$ Neonates are special population, whose cardiomyocytes are softer with less contractile tissue and lower energy reserves. Longer CPB time leads to poor myocardial cell compliance and insensitivity to drugs, and these lead to heart failure controlled by drugs difficultly after open heart surgery. According to the latest statistics from ELSO 2017, the neonatal survival rate of CHD is $47 \%$ and discharge rate is $39 \%{ }^{8}$ In our study, although the survival rate of neonate is as high as $52.17 \%$, there are many risk factors that affect the outcomes. 


\section{Metabolic Acidosis}

Studies have shown that hyperlactic acidosis is an effective biomarker, and the severity of pre-ECMO arterial acidosis is related to outcomes. ${ }^{9}$ In our study, five patients with lactic acid $<10 \mathrm{mmol} / \mathrm{L}$ before ECMO were discharged, while in 18 patients with lactic acid $>10 \mathrm{mmol} / \mathrm{L}$, only 7 survived. This suggests that higher lactate levels before ECMO is an independent risk factor for poor outcomes. There was a significant difference in the highest lactate, the levels of ECMO 12 and 24 hours and the lactate clearance time between two groups $(p=0.03,0.005$, 0.001 , and 0.036 , respectively). The results are similar to those findings of the reports. ${ }^{10,11}$ Fux et $\mathrm{al}^{12}$ analyzed VA-ECMO patients and found that ischemic heart disease and arterial lactate were independent predictors of 90-day mortality. The 90-day survival rate of lactic acid $>10 \mathrm{mmol} / \mathrm{L}$ was lower than patients with lactic acid $<10 \mathrm{mmol} / \mathrm{L}$ before ECMO (13 and $55 \%$, $p<0.001$ ). If the lactate remained at $3 \mathrm{mmol} / \mathrm{L}$ after 48 hours, the 30 -day mortality rate is $52 \%$. Other articles ${ }^{13,14}$ suggested that persistent metabolic acidosis after ECMO reflects the severity of ischemia and hypoxia and confirmed that the peak lactate level affects the survival rate. Therefore, early application to reverse poor perfusion and prevention high lactate are critical factors for successful outcomes following ECMO.

\section{ECMO Duration}

Our findings are consistent with the results reported in the literature on ECMO support after cardiac surgery ${ }^{14}$ : Compared with the survivors, ECMO duration were significantly longer in nonsurvivals $(p=0.046)$. ECMO duration is directly linked to the other complications and survival rate. The ELSO data analysis also showed that ${ }^{15}$ : The highest survival rate for the ECMO weaning is at the fourth day, and the shorter ECMO duration resulted in higher mortality due to inadequate support. In the group of neonates assisted for 4 to 12 days, the survival rate decreased gradually with the longer duration, especially in children with assist time $>7$ days. ${ }^{13}$ Long-term assistance means poor recovery of heart function, especially in neonates after cardiac surgery. If accompanied with serious complications, ECMO could not successfully wean off in shorand long-term assist devices, or switch to left ventricular assist device as bridge to heart transplantation should be considered. ${ }^{16}$ In this group, there were eight patients with assist time of 1 to 3 days and five survived, nine patients assisted for 3 to 5 days and seven patients discharged; however, six patients assisted for more than 5 days and all died $(p=0.01)$. Our results were close to the ELSO statistics, indicating that ECMO duration was one of the main factors affecting survival.

\section{Bleeding}

Complications in the ECMO support are important predictors of poor outcomes. The most common complication in this study was bleeding. Sixteen patients experienced severe surgical site bleeding requiring explorations and 11 patients died. Neonates have small volume of circulating blood and immature blood coagulation mechanism, ECMO prefilling dilute the anticoagulant components, and longer CPB time destroyed blood components. Improving supplement coag- ulation components and try to correct coagulation defects are very important. ${ }^{13}$ Four patients experienced severe GI bleeding and only one survived, and two patients with ECPR time more than 30 minutes before ECMO. GI bleeding resulted from infection, ischemia and hypoxia, feeding, and blood flow to premature labor when patients were under critical illness. Studies have shown that 90 to $95 \%$ necrotizing enterocolitis (NEC) occurs in premature and low-birthweight infants with a gestational age of less than 36 weeks, which is the result of a combination of risk factors. ${ }^{17}$ The literature reports that feeding factors (type, speed, and concentration) are intrinsically linked to the occurrence of NEC because the neonatal digestive system is immature and susceptible to ischemic injury, and digestive enzyme activity is low, which will eventually increase the incidence of NEC. ${ }^{18}$

\section{Residual Malformations}

Residual cardiac malformations were found in six patients by transthoracic echocardiography. One neonate's malformation was corrected during ECMO and discharged. Other patients were weaned successfully, but died finally due to recurrent heart failure. There was a statistically significant difference between the survival and nonsurvival $(p=0.04)$. Studies ${ }^{19,20}$ have reported that one-quarter of children with ECMO support after open heart surgery have residual anatomical problems. All residual lesions should be evaluated actively, neonates who failed to wean from ECMO without a clear cause were investigated for presence of residual lesions. Our center uses transthoracic echocardiography and cardiac catheterization to evaluate residual lesions. A transthoracic echocardiography imaging study was undertaken during the process of ECMO and was the initial imaging study for evaluating residual lesions. A cardiac catheterization imaging study was undertaken when the echocardiographic results were inconclusive and neonate was unable to be weaned from ECMO support successfully. Early examination and interventional therapy were related to better clinical outcomes. Therefore, residual malformations should be discovered as soon as possible, and active intervention can improve cardiac function.

\section{Summary}

ECMO was an effective technology to support the neonates with cardiopulmonary failure after open heart surgery to wait for heart function recovery. Control the lactate acidosis and surgical site bleeding event may be helpful for patients' recovery.

\section{Authors' Contribution}

Yu Xin-di designed the study and drafted the manuscript; Yang Yin-yu, Zhang Wei, Guo Zheng, Shen Jia, Zhuoming $\mathrm{Xu}$, and Haibo Zhang performed data collection; Wang Wei helped perform data analysis. All authors read and approved the final manuscript.

\section{Preprint Disclosure}

A previous version of this manuscript was put on the Authorea preprint platform on September 16, 2020, for a 
different open review process with another journal. The manuscript itself was not formally published somewhere else.

Funding

Funded by National Natural Science Foundation of China (grant number 82070430).

\section{Conflict of Interest}

None declared.

\section{References}

1 Torres-Andres F, Fink EL, Bell MJ, Sharma MS, Yablonsky EJ, Sanchezde-Toledo J. Survival and long-term functional outcomes for children with cardiac arrest treated with extracorporeal cardiopulmonary resuscitation. Pediatr Crit Care Med 2018;19(05):451-458

2 Wallinder A, Pellegrino V, Fraser JF, McGiffin DC. ECMO as a bridge to non-transplant cardiac surgery. J Card Surg 2017;32(08):514-521

3 Bartlett RH, Gazzaniga AB, Jefferies MR, Huxtable RF, Haiduc NJ, Fong SW. Extracorporeal membrane oxygenation (ECMO) cardiopulmonary support in infancy. Trans Am Soc Artif Intern Organs 1976;22:80-93

4 Azizov F, Merkle J, Fatullayev J, et al. Outcomes and factors associated with early mortality in pediatric and neonatal patients requiring extracorporeal membrane oxygenation for heart and lung failure. J Thorac Dis 2019;11(Suppl 6):S871-S888

5 Burke CR, McMullan DM. Extracorporeal life support for pediatric heart failure. Front Pediatr 2016;4:115

6 Erdil T, Lemme F, Konetzka A, et al. Extracorporeal membrane oxygenation support in pediatrics. Ann Cardiothorac Surg 2019;8 (01):109-115

7 Djordjevic I, Sabashnikov A, Deppe AC, et al. Risk factors associated with 30-day mortality for out-of-center ECMO support: experience from the newly launched ECMO retrieval service. J Artif Organs 2019;22(02):110-117

8 Thiagarajan RR, Barbaro RP, Rycus PT, et al. ELSO member centers. Extracorporeal Life Support Organization Registry International Report 2016. ASAIO 2017;63(01):160-167

9 Avalli L, Sangalli F, Migliari M, et al. Early vascular complications after percutaneous cannulation for extracorporeal membrane oxygenation for cardiac assist. Minerva Anestesiol 2016;82(01): 36-43

10 Choi MS, Sung K, Cho YH. Clinical pearls of venoarterial extracorporeal membrane oxygenation for cardiogenic shock. Korean Circ J 2019;49(08):657-677

11 Napp LC, Kühn C, Bauersachs J. ECMO in cardiac arrest and cardiogenic shock. Herz 2017;42(01):27-44

12 Fux T, Holm M, Corbascio M, Lund LH, van der Linden J. Venoarterial extracorporeal membrane oxygenation for postcardiotomy shock: risk factors for mortality. J Thorac Cardiovasc Surg 2018; 156(05):1894-1902.e3

13 Alsoufi B, Awan A, Manlhiot C, et al. Does single ventricle physiology affect survival of children requiring extracorporeal membrane oxygenation support following cardiac surgery? World J Pediatr Congenit Heart Surg 2014;5(01):7-15

14 Gupta P, Robertson MJ, Rettiganti M, et al. Impact of timing of ECMO initiation on outcomes after pediatric heart surgery: a multi-institutional analysis. Pediatr Cardiol 2016;37(05): 971-978

15 Smith M, Vukomanovic A, Brodie D, Thiagarajan R, Rycus P, Buscher H. Duration of veno-arterial extracorporeal life support (VA ECMO) and outcome: an analysis of the Extracorporeal Life Support Organization (ELSO) registry. Crit Care 2017;21 (01):45

16 Kuraim GA, Garros D, Ryerson L, et al; Western Canadian Complex Pediatric Therapies Follow-up Program. Predictors and outcomes of early post-operative veno-arterial extracorporeal membrane oxygenation following infant cardiac surgery. J Intensive Care 2018;6:56

17 Teišerskas J, Bartašienė R, Tamelienè R Associations between red blood cell transfusions and necrotizing enterocolitis in very low birth weight infants: ten-year data of a tertiary neonatal unit. Medicina (Kaunas) 2019;55(01):E16

18 Patel RM, Knezevic A, Shenvi N, et al. Association of red blood cell transfusion, anemia, and necrotizing enterocolitis in very lowbirth-weight infants. JAMA 2016;315(09):889-897

19 Agarwal HS, Hardison DC, Saville BR, et al. Residual lesions in postoperative pediatric cardiac surgery patients receiving extracorporeal membrane oxygenation support. J Thorac Cardiovasc Surg 2014;147(01):434-441

20 Guo Z, Yang Y, Zhang W, et al. Extracorporeal cardiopulmonary resuscitation in children after open heart surgery. Artif Organs 2019;43(07):633-640 